\title{
The aggregation of information qualities in collaborative software
}

\section{Désirée I. Christofzik and Christian Reuter*}

Research School Business and Economics,

University of Siegen,

Am Eichenhang 50,

D-57076 Siegen, Germany

E-mail: desiree.christofzik@uni-siegen.de

E-mail: christian.reuter@uni-siegen.de

*Corresponding author

\begin{abstract}
Collaborative software supports teams involved in a common task in generating and sharing information over geographic distances. Such software is used in the cooperation between organisations, companies or individuals. The overall quality of the resulting information product depends on the quality of the individual contributions as well as on an underlying consolidation process. We therefore present different 'composition functions' indicating how the qualities of the contributions by single actors $\left(q_{i}\right)$ influence the quality of the aggregated information $(Q)$. Based upon a qualitative empirical study of inter-organisational crisis management in Germany we match use cases with those composition functions and derive implications for the design of collaborative software.
\end{abstract}

Keywords: collaborative software; computer supported collaborative work; composition functions; information quality; crisis management; aggregation technologies.

Reference to this paper should be made as follows: Christofzik, D.I. and Reuter, C. (2013) 'The aggregation of information qualities in collaborative software', Int. J. Entrepreneurial Venturing, Vol. 5, No. 3, pp.257-271.

Biographical notes: Désirée I. Christofzik holds a Master's degree in Economics and is currently a PhD Fellow at the Research School Business and Economics at the University of Siegen. Her research focus is on public economics and policy, especially on publicly provided goods.

Christian Reuter studied information systems at the University of Siegen and École Supérieure de Commerce de Dijon, France and graduated with a Master of Science. After his studies, he gained experience in business and IT consultancy. He is currently working at the University of Siegen in the research field of Computer Supported Collaborative Work (CSCW) and Human Computer Interaction (HCI), especially for crisis management.

This paper is a revised and expanded version of a paper entitled 'Fostering collaborative information quality: composition functions and their impact on the design of inter-organisational collaborative software' presented at 1st Interdisciplinary Workshop of the Graduate Research School Business and Economics (RSBE) on, 'Decentralisation and networks', University of Siegen, 24-25 November 2011. 


\section{Introduction}

In increasingly complex and decentralised environments cooperation between different partners and collaboration of enterprises and organisations are of growing importance. In small- and medium-sized enterprises, inter-firm collaboration is a common approach to foster competitiveness (Rosenfeld, 1996), as well as for business ventures dealing with the typical limitations of start-ups (Mainela and Puhakka, 2011). Empirical evidence suggests that the performance of a start-up is fostered by business networks and associations (Davidsson and Honig, 2003) as well as by well-connected venture capital networks (Hochberg et al., 2007) or co-investment networks of business angels (Böert and Werth, 2012). Web 2.0 technologies, such as collaborative software (Johansen, 1988), may act as a facilitator to encourage entrepreneurial opportunities (Le and Tarafdar, 2009; McAfee, 2006). In many cases, especially if information, resources or competences are distributed, collaboration is the only way to solve a problem.

In our paper we will consider such a case and illustrate that inter-organisational collaborative software can support different participants in merging decentralised information. Designing such a system requires a profound understanding of the underlying processes, especially of how the aggregate level of information is assembled and how individual contributions can be enhanced through the implementation of such an infrastructure. To identify appropriate scenarios we have conducted a qualitative empirical study using the example of inter-organisational collaboration in crisis management in Germany. We assume that it is possible to transfer our implications to other forms of collaborative systems as the essential processes are comparable whenever information is exchanged between organisations, companies as well as between individuals or interest groups.

When organisations, enterprises or individuals work together, they combine individual contributions to create some form of collective good. This is connected with Olson's (1965) work on collective action or the economic literature on the private provision of public goods (Bergstrom et al., 1986). A matter of particular interest is the production process of such an aggregated commodity. In our example, this commodity is consolidated information, which is collected by means of an IT-based collaboration system. In the following sections, we will present different composition functions to give an understanding of the underlying consolidation process and to derive practical implications that are connected with the assumptions about the production process. We will show that this choice has a direct influence on the implementation process of such systems.

The paper is organised as follows: section two characterises inter-organisational collaborative software with special reference to our example, the crisis management collaboration system Infostrom (Wiedenhoefer et al., 2011). Furthermore, possible composition functions based upon Hirshleifer (1983) and Cornes and Sandler (1996) are introduced. For these functions, optimisation criteria are identified in section three. Besides, qualitatively and empirically ascertained application scenarios are revealed to clarify these criteria and the implications of the composition functions. A transfer to other applications consummates this chapter. Section four is the conclusion. 


\section{Characterisation of an inter-organisational collaboration system}

The electricity network is one of the most important infrastructures in modern industrialised societies. In everyday life, the population and the whole economy depend to a great extent on a solid infrastructure and especially in the case of breakdowns in power supply, they become aware of their dependence on electricity (Birkmann et al., 2010). Coping and recovery work has a high priority in order to regain electricity and decrease the consequences of the breakdown. As information and resources are distributed, inter-organisational collaboration between all stakeholders in these decentralised organisations - especially the fire brigade, the police, the county administration, the energy network operator, companies depending on power supply and affected citizens - are necessary to effectively handle the situation. One possible approach to support the essential cooperation, to foster collaboration and extend communication is an IT-based infrastructure for crisis management (Wiedenhoefer et al., 2011). By means of this system, important information can be shared, contact details can be identified or content generated by citizens can be utilised.

The regional network of crisis management is comparable to regional clusters, such as regional networks of companies. Technical approaches aiming at fostering awareness and collaboration among those companies are rare. Reichling et al. (2010) present an approach to foster interconnectedness and to strengthen existing network ties using a software to help find expertise for specific tasks among the companies. Those are especially important for SME because they usually have limitations, e.g., in workforce. In this paper, we also focus on networks containing small entities such as SME, which could be supported by collaborative software.

Even though our empirical study allows us to study the case of crisis management in more detail, we will also discuss conclusions for other forms of collaborative work, for examples cooperation of nascent entrepreneurs or co-investors into start-ups. As empirical evidence shows that better connected investors show a higher performance (Hochberg et al., 2007; Böert and Werth, 2012), a possibility to foster the quality of such networks may be the implementation of collaborative software. The same applies to nascent entrepreneurs. Davidsson and Honig (2003) show empirically that nascent entrepreneurs who are member of a business network are more successful. They propose 'to develop business centres that focus on the facilitation of community and networking activities' [Davidsson and Honig, (2003), p.303]. We will return to these examples in section three.

As in company networks, the actors in crisis and disaster management are generally independent and decentralised organisations with shared responsibilities, so that they need to collaborate, especially in the case of disasters. Different access to information may impede the communication between the organisations and lead to a delayed solving of the problem (Kapucu, 2006; Lundberg and Asplund, 2011). The pooling of information using collaborative software is a possibility to facilitate acting in the case of a crisis. The contributions of the individual organisations are an investment in a collectively provided good, which allows coping with a crisis in a simplified and more rapid way because of the faster availability of the required information.

The information created jointly by all organisations within the cooperative system has characteristics of a public good, but non-members can be excluded from using the information. An active contribution of information in this context is largely voluntary. ${ }^{1}$ If 
an organisation contributes individual information, it privately provides a public good (Bergstrom et al., 1986).

In the following, we will focus on the provision of information and thus the production process of collectively produced information. Contributing information is associated on one hand with costs arising from the time spent on posting such contributions, which is especially relevant for organisations with limited resources and workforce. Also the implementation of such a technical innovation has to be taken into account. On the other hand, exposing information involves obstacles, especially if information is sensitive or confidential or potential competitors participate in the collaborative system. Moreover, the relevance and usefulness of the information provided can be uncertain for future events, in particular in case of specific information.

But moreover, the utility of the own investment depends significantly on the activities undertaken by other organisations. If only one partner participates actively, utility will be lower than in case of a broad participation of all relevant cooperation partners. Nevertheless, the quality will not necessarily be increased through an expansion of the activities of all organisations. Therefore, the traditional aggregation technology used in economic theory dealing with public goods - where the aggregated quality is achieved through the unweighted sum of the individual contributions (Samuelson, 1954) - is certainly not the only appropriate modelling. Especially for inter-organisational collaboration, alternative aggregation functions may be of practical importance. These functions help to formally describe the result of the collective action. Thereby, the formulae clarify the underlying consolidation process and allow us to draw conclusions on the individual contributions and how they can be enhanced by adjusting the design of the collaborative software. Based upon Hirshleifer (1983) we refer to them as (social) composition functions or with reference to the similarities to production processes as aggregation technologies. In the following section, some extreme cases of these functions are described and illustrated using applications from crisis management.

\subsection{Measuring information quality}

In order to stimulate active contributions by the individual organisations, it is inevitable to identify a method to evaluate the aggregated information's quality. Only this allows us to analyse measures by which the collaborative software can be optimised. Therefore, it is crucial to determine how to evaluate the quality of a specific contribution, but also the benefit of collaboratively generated information to the network. The focus of this paper is on the second aspect.

According to Wang and Strong (1996) data quality is defined as 'data that are fit for use by information data'. According to DIN (2004), the term information quality is defined as 'the entirety of quality attributes of information or as an information process which refers to its appropriateness and quality for the accomplishment of a given task'. Different taxonomies exist for the determination of information quality, for example the extended ISO model (Zeist and Hendriks, 1996), which measures information quality on the basis of characteristics such as functionality, reliability, efficiency, usability, maintainability and transferability. The model of information quality (Wolf, 1999) takes into account content, relevance for the decision, time, location, amount, form and profitability; the conceptual framework of data quality (Wang and Strong, 1996) is based on intrinsic, contextual, representational and accessibility concerned data quality. The quality of single contributions is influenced by various aspects; approaches to calculate a 
quality score, e.g., of Friberg et al. (2011), Bharosa et al. (2009) or Naumann and Rolker (2000), indicate the high complexity of consistently evaluating information quality. However, the quality of the specific pieces of information is only one part of the collaboratively generated information quality.

Such a specific piece of information becomes part of the aggregate information when it is published in collaborative software, no matter how its quality has been measured or determined. Therefore, it is crucial to identify the underlying production technology, which is the foundation of a collectively generated good and determines how the interdependencies between the contributors are depicted. Cornes and Sandler (1996) point out that the appropriate institutional structures depend on the properties of the aggregation function. Thus, their identification is a key factor when developing incentive schemes.

\subsection{Composition functions}

Cornes and Sandler (1996) and Cornes and Hartley (2007) show that various composition functions can be illustrated using a generalised CES (constant elasticity of substitution) function and varying the exogenous parameters $\alpha$ (indicating if the average or the sum is decisive) and $v$ (influencing the elasticity of substitution). Considering $i=1, \ldots, n$ single organisations contributing individual information with quality $q_{i}$, the quality of the aggregate information $Q$ results from the following expression.

$$
Q=\alpha\left[\frac{1}{n} \sum_{i=1}^{n} q_{i}^{v}\right]^{\frac{1}{v}}
$$

The speed of availability is one important component of information quality. In crisis management, information often has to be disposable on short notice. A piece of information which is rapidly available, but with lower values in other components may be more relevant than high-quality information which is available at a later time. Though the speed of availability is not explicitly included in the formulae, the individual quality level $q_{i}$ can be weighted with a time or discount factor in situations where this criterion is necessary.

Keeping this in mind, one possibility to calculate the aggregate information quality is to use the unweighted sum of the separate contributions $q_{i}$. In economics, this is the assumption of the standard public good framework (Samuelson, 1954). The contributions of the participants are thereby commutative. Hence, it is irrelevant by whom an individual contribution is made and how the sum is distributed across the contributors (Cornes and Sandler, 1996). This formula might be true for gathering general information for which the information of the individual organisations does not differ factually or when creating interfaces and processes for the exchange of organisation-related data. Using the CES function mentioned above, the summation technology is derived if the exogenous parameter $\alpha$ is equal to $n$ and $v=1$ which implicates a maximal elasticity of substitution:

$$
Q=\sum_{i=1}^{n} q_{i} .
$$


Especially in the context of crisis management, taking into account the necessity of cooperative work, an alternative composition function is conceivable which assumes that the least information of a specific organisation is equal to the overall result. Collective information will only be useful if information of all partners is available. The expansion of one organisation's activity will only increase the quality if the other organisations make their contributions, too. Vicary (1990) illustrates that such an aggregation technology is a suitable model for many aspects of teamwork. If the information of the organisations differs or is built upon one another and cooperation is necessary for a crisis' solution, this seems to be an appropriate assumption. For instance, if the collaboration of all participating organisations is necessary to restore an infrastructure and one participant's information is not available, all other contributions do not have any benefit at all in this extreme case. With reference to historical examples, Hirshleifer (1983) reveals that the conditions for modelling a weakest-link technology seem to be likely in the case of catastrophes. If so, the production process would be characterised by a formula, which is determined by the least of the contributed pieces of information. The weakest-link formula arises when the exogenous parameters of the CES function (1) are set to $\alpha=1, v \rightarrow-\infty:^{2}$

$$
Q=\min _{i}\left(q_{1}, \ldots, q_{i}, \ldots, q_{n}\right)
$$

Closely related to this composition function and less extreme is the assumption of a weaker-link function. This is a convex technology for transforming individual contributions into the aggregate information and emerges if $\alpha=1$ and $-\infty<v<1$.

A further possibility of modelling the aggregation process is a best-shot formula, which assumes that the quality is solely derived by the best single contribution. This technology might especially be appropriate in the case of collective information which does not arise as a result of interaction between multiple participants, but which is referred to specific information that has the same relevance to all organisations. The best-shot technology can be expressed using expression (1) and setting the parameters $\alpha=1$ and $v \rightarrow \infty$ :

$$
Q=\max _{i}\left(q_{1}, \ldots, q_{i}, \ldots, q_{n}\right)
$$

Better-shot functions $(\alpha=1,1<v<\infty)$ describe non-convex social composition functions and are less extreme than the assumption of a best-shot technology.

Compared to the standard formula of summation, Hirshleifer (1983) shows that the undersupply of a public good is decreasing in case of a weakest-link formula. It is increased if assuming a best-shot technology. This becomes obvious when considering the possibility of free-rider behaviour and the influence of one's own action on the overall result. In case of a weakest-link technology, refusing to contribute has a substantial impact on the quality of the public good. In doing so, free-riding is not possible as the public good has no quality at all. In case of a best-shot technology, the individual utility arises from the best information of another organisation if not contributing. Then, participants will only contribute information if they can expect a higher benefit from sharing their own information than from using the information, which is already available. However, established schemes of contribution do not arise as a result from identifying a technology, but it affects the requirements on institutional structures that can foster a more efficient contribution (Cornes and Sandler, 1996). 


\section{Implications of different composition functions}

Considering the different cases of social composition functions shown by Cornes and Hartley (2007), it becomes apparent that different implications for optimising an inter-organisational communication system arise. In this chapter, therefore, we look at scenarios we have identified by conducting a qualitative empirical study using the example of inter-organisational collaboration in crisis management in Germany. Based on these scenarios, we have derived potential measures to optimise the quality level of the aggregate information and to identify specific requirements for information systems that are referred to as technical problem-solving approaches and concrete implications for the design of application systems. Even though rather mixed forms of the technologies presented exist in reality, an orientation towards these cases may foster the understanding of the meaning of the aggregation forms.

\subsection{Empirical basis for identifying the aggregation form}

The description of the application scenarios and their reference to the aggregation forms are based on qualitative-empirical studies in the field of inter-organisational crisis management. These studies were carried out in two counties of North Rhine-Westphalia, Germany, in the years 2010 and 2011. Various actors of emergency response agencies, such as fire service, police, aid organisations, public administration and energy network operators, were involved. In crisis situations, they are organised in a crisis management group of the public administration, an incident command of the non-police agencies as well as in an incident command of the police's emergency response. Typically, these teams partly consist of representatives of other relevant organisations who are responsible for the transmission of information.

Document analyses, observations, semi-structured interviews and group discussions were carried out as part of the data acquisition. The aim of the document analysis was to gain an overview of the organisations in crisis situations and their information exchange. Altogether 19 documents (laws, decrees, edicts, guidance, training documents) were analysed which give a description of the activities in crisis management. The purpose of the observations was to obtain insights into the practical work in inter-organisational crisis management. They were conducted in a county's control centre during a normal working day (observation period: nine hours), in a crisis committee and in an incident command during a training session of crisis communication (four hours) and an actual larger incident (six hours). The interviews' objective was to comprehend working practices and to identify inter-organisational demands for information as well as potential IT support in crisis management. Twenty one interviews, lasting an average of 1.5 hours, were accomplished with all relevant actors in crisis management. The group discussions were aimed to grasp the communication practices in cross-organisational crisis communication. Four group discussions were held with leading actors from the county administration, police, fire services and the German Red Cross, which took about four hours each. The goal of the empirical studies was to analyse information and communication processes in order to determine potentials for optimising the exchange of information with the aid of a collaborative software (Ley et al., 2012). 


\subsection{Initiating an automated exchange of information and target-group-specific display}

Scenario: A use case, which we observed, is the manual or automated provision of information in the control centre during severe weather conditions. The activities of the incident command and the control centre require a great amount of information. Some of this information is available via information systems; additional information can be searched and viewed online, other information has to be inquired manually of the providers or is transferred to the incident command via e-mail. The handling of severe weather conditions by the control centre of the non-police emergency response agencies is a practical example. After having received consistent weather alerts from the German Meteorological Service and two private weather services, the situation is evaluated by the information service of the control centre. For this purpose and besides 'official' information systems, additional information sources, e.g., webcams directed towards the weather front, online retrievable water levels or weather radars, are consulted, depending on the control centre's dispatcher on duty. Generally, plenty of external online resources are utilised in the course of a situation that can lead to a major catastrophic event, with the result that the overview of the monitor is disturbed by the large number of open windows, which is perceived negatively.

Composition technology: When looking at the empirical data we see that the variety of sources makes it necessary to select the received information. However, additional sources of information can increase the quality of the aggregated information even in the case of redundant information. They can increase the possibility of a correct evaluation of the situation. Furthermore, information from multiple sources is gathered to obtain additional data considering various aspects in order to achieve a correct assessment, such as webcams or water levels. The form of aggregation thus depends not only on the scenario, but also on the specific question. Summation seems to be a reasonable aggregation form, because the posts are commutative. However, weaker-link technologies also arise if specific data can only be provided by certain actors, for example, and then missing pieces of information can strongly affect the overall quality. In this case, the possibility of substituting information decreases.

Supportive approach: A possible approach to support the staff of the agencies would be a system that integrates information from different sources and providers (Ley et al., 2012). An automated exchange of information on roadblocks delivered by police and fire service, on areas of power outages relayed by energy network operators, on weather data conveyed by the German Meteorological Service or on water levels passed on by the regional environment agency would be useful. Here, the aim is to pool and to integrate existing information once, instead of being forced to retrieve it manually. Because a reasonable use of the entire information is only possible if the amount of data is manageable for the user, mechanisms for the visual display must be created which meet the needs of the respective target groups, tasks and incidences. Customisable displays appear to be useful (Lieberman et al., 2006) which are configured on the basis of the user's work tasks. A further useful realisation is a selection of user-specific services, which is realised by a flexible implementation as for instance a service-orientated architecture. The users could select the appropriate services out of a repository and compose them on their personal display (Doerner et al., 2009). When presenting this information on a map, it should be possible to show or hide it depending on the respective role and the actual situation. Besides these manual setting options for the 
users, automatisms for the display of information on the basis of special incidents are conceivable, for example a visual display showing webcams, which are directed to where the severe weather is reported. Because of disjoint pieces of information, which frequently occur, and different areas of operations, the entire information's quality arises as a result of the summation of its components' quality. In other words, single pieces of information contribute to the evaluation of the situation based on different aspects.

\subsection{Identifying missing information about personal or technical resources in inter-organisational situation maps}

Scenario: In crisis management there is a great amount of technical and personnel resources that are used in various scenarios. Especially during large operations, it is common to provide administrative assistance depending on one's own workload and to try compensating resource bottlenecks. Because of their lower number of staff, for instance, the police rely on the fire service to build up barriers. The management of free resources is inevitable. However, this is carried out manually and, to some extent, requires a significant amount of effort, because of juridical regulations, the non-existence of GPS transmission of the vehicles' locations as well as the lack of a cross-organisational, automated matching of the resources' availabilities.

Composition technology: In this case, it is important to gather the information of all relevant organisations and therefore, the active participation of all actors is crucial. The crisis management system is only useful if it includes reliable data. If a decision is made and information of some organisations is missing or if missing information has to be collected manually, the utility of the system declines. This scenario can be described by a weakest-link or weaker-link composition function.

Supportive approach: An approach to support this cooperation would be a central information system for the management of free resources in crisis management. A collaborative overview of the situation would be conceivable, too. The exchange of information, which is required at that point, should be conducted (semi-)automatically by the individual organisations in order to reduce manual efforts. A central information system such as that, would be useful if and only if really all resources were contemporarily recorded in it and if it was not necessary to obtain additional information from other organisations as and when required. If this was not the case, it would not reduce the efforts at all because the manual obtaining of information and the use of the information system would take place in parallel and the overview of the situation would not be complete. In this use case it is obvious that the information's quality is significantly affected by its weakest component. Here, it is of key importance to enable an awareness (Dourish and Belotti, 1992) of the other actors' activities and to visualise information gaps. These gaps should not only be identified by chosen organisations but by all participants in order to fill them with additional information.

\subsection{Selecting relevant information generated by citizens in crisis management}

Scenario: Citizen-generated content in social software is a further possibility of getting important information. Social software comprises applications, which are attached to the internet and enables contacting and exchange among various participants. During crises it is possible to supply family, friends and the public with information. Exemplary crises, in 
which social software was used, were the love parade disaster in Germany and the volcanic eruptions in Iceland which both happened in 2010 (Reuter et al., 2012): Facebook (a digital social network), Twitter (a service for publishing short messages with a maximum length of 140 characters which can be shown by other internet users on the basis of search tags), YouTube (a platform for videos) and Flickr (a service for photos) were used extensively. The information on these platforms was provided by the affected persons and accessed by a large number of people. Depending on the crisis' range, the amount of news and photos provided can hardly be overseen. Because the news is provided by citizens, different qualities and overlapping pieces of information exist. Today, this kind of information is being used and evaluated by the police, for example in the case of demonstrations. However, perceived flaws are the amount of news, which has to be examined, and the quality, i.e., the information content of the single news. Our empirical study (Section 3.1) made obvious that 'at best $5 \%$ of the news can contribute to a situation's evaluation'.

Composition technology: This example reveals that not the mass of the citizens' contributions generates additional value in crisis management, but that the best piece of information is crucial. ${ }^{3}$ For instance, not a hundred pictures of a fire are needed, but only a few good ones from different perspectives. This is one example for a best-shot or better-shot composition function.

Supportive approach: A possible approach to technically support the control centre's staff is the identification of the best-shots by evaluating the single pieces of information. This can be made automatically, for example on the basis of meta-data about the location and the time or on the basis of Retweets (Starbird and Stamberger, 2010). Retweets are literally repeated news of other users that indicate a high importance of specific information. Manual evaluations by actors in crisis management or by citizens who correct faulty information by themselves on the basis of collective intelligence (e.g., Wikipedia) are useful, too (Vieweg et al., 2008). The system should highlight the qualitatively best pieces of information in order to enable their utilisation. Besides these mechanisms for evaluations, the support of citizens when transmitting relevant information is another solution. For instance, photographing of relevant pictures could be supported by a special application for mobile phones, which on the one hand could render assistance when recording relevant information and on the other hand can ensure that all relevant meta-data are transmitted. In addition to that, users could see which incidences have already been reported in order to prevent repeated reports about the same incident and to enable confirmations. Frequently overlapping pieces of information and different qualities explain that only the best pieces are of relevance in such a use case. It shows that information quality can be especially influenced by the quality of single messages and not only by their amount. An evaluation and a selection of available contributions can foster the clarity and accessibility.

\subsection{Discussion and transferability to other domains}

The composition functions mentioned above are relevant in the evaluation of the aggregated information's quality in various fields of application. These formulae thereby only express the description of a state. Various combinations and mixed forms may be relevant in reality, but it can be approximated which function describes reality best in order to derive design requirements for technical solutions. Therefore, the issue has to be identified at first in order to match the single pieces of information. This can be 
accomplished by a simulation of possible crises (Reuter et al., 2009), which can give clues about the character and the interdependencies of required information.

- The composition function of summation is appropriate, if the sum of individual qualities determines the overall information's quality and the contributions are perfect substitutes. We used the example of automated provision of information from different sources to clarify this case (Section 3.2). Requirements for collaborative software are to arrange information clearly, to enable a simple selection and target-group, task- and incident-specific display of information.

- The composition function weakest-link is appropriate, if the least piece of (disjoint) information is the significant factor for the determination of the information's quality. In this context, we analysed the example of administration of technical and personal resources (Section 3.3). Requirements for collaborative software are to visualise gaps, claim missing information specifically and to create stimuli for providing entire information.

- The composition function best-shot is appropriate, if and only if the usage of only the best piece of (overlapping) information comes into consideration and the second best piece hardly has any relevance at all. We used the example of the utilisation of content generated by citizens in Social Software (Section 3.4). Requirements for collaborative software are to classify and evaluate incoming information and to enable easy selection of the best pieces of information.

Figure 1 illustrates our use cases, the requirements obtained and the composition functions dependent on the parameter $\mathrm{v}$ which influences the possibility of substitution.

Figure 1 Scenarios, requirements and composition functions dependent on $v$ (influencing the possibility of substitution)
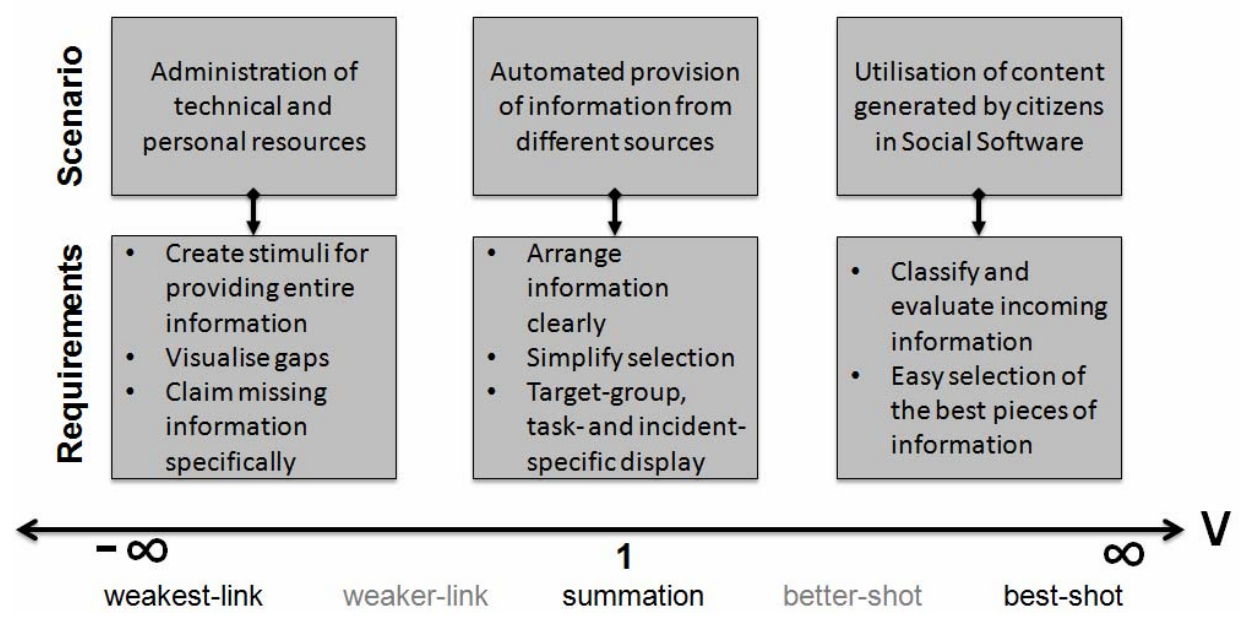

When we look at other forms of collaborative systems, for example inter-firm collaborations (Davidsson and Honig, 2003) or co-investment networks (Böert and Werth, 2012), the requirements are identical. It does not matter whether the cooperation is supported by such collaborative software as presented in this paper or by other 
technical means. If we consider for example a venture capital network (Hochberg et al., 2007), which exchanges information how to improve the performance of start-ups using a bulletin board or other simple technical implementations, the requirements to foster the quality of the network depend on the mentioned mechanisms. The same applies to community and network activities of nascent entrepreneurs who 'work in autonomous, distantly separated environments' [Davidsson and Honig, (2003), p.303] as business networks seem to be a main driver of success for emerging firms. Collaborative software can facilitate such exchange of information. Contingent upon the possibility of substitution, the incentives to provide information differ as shown above. In weakest-link situations, missing information of one investor or partner is the critical part and has to be highlighted, whereas in best-shot situations a selection and classification process of information reduces redundancies and search time. If a summation technology arises as appropriate description and the elasticity of substitution is maximal, it does not matter who provides the piece of information, but a simplified selection and a target-group, task- and incident-specific display enhances the quality of the system.

It has been shown that entirely different requirements for the design of a collaborative software in crisis management, or other applications, arise as a result, depending on the aggregation technology. That is why a profound investigation of the context of single pieces of information seems to be a reasonable approach to extend the requirement analysis in every kind of information and cooperation system. We assume that it is possible to transfer our implications into other forms of collaborative software, as the essential processes are comparable whenever information is composed of information from different sources.

\section{Conclusions}

Our analysis has shown that the identification of information composition functions should be taken into consideration when designing inter-organisational collaborative software. These functions determine the impact of the specific pieces of information on the quality and usefulness of the aggregated information and affect the essential incentives to foster the quality of the collaborative system.

We have analysed the relevance of identifying and investigating collective information qualities using qualitative empirical studies and the example of inter-organisational crisis management in Germany. Based upon the economic literature on the private provision of public goods we have illustrated different composition functions using a generalised CES function to show characteristics of specific pieces of information and their aggregations. On the basis of these use cases, implications for the design of collaborative systems have been derived to emphasise the importance of identifying characteristics of collectively provided information.

It has been shown that entirely different requirements for the design of collaborative software arise depending on the underlying consolidation processes. Therefore, a profound investigation of the application scenario is useful to extend the requirement analysis in every kind of information and cooperation system in order to implement appropriate measures. Our implications may be transferred to other forms of collaborative software, as the essential processes are comparable whenever information is composed of information from different sources and information is exchanged between organisations or companies as well as between interest groups or individuals. 


\section{References}

Bergstrom, T., Blume, L. and Varian, H. (1986) 'On the private provision of public goods', Journal of Public Economics, Vol. 29, No. 1, pp.25-49.

Bharosa, N., Van Zanten, B., Zuurmond, A. and Appelman, J. (2009) 'Identifying and confirming information and system quality requirements for multi-agency disaster management', Proceedings of the 6th International ISCRAM Conference, Gothenburg, Sweden.

Birkmann, J., Bach, C., Guhl, S., Witting, M., Welle, T. and Schmude, M. (2010) 'State of the Art der Forschung zu kritischen Infrastrukturen am Beispiel Strom/Stromausfall', Schriftenreihe Sicherheit, Forschungsforum Öffentliche Sicherheit der FU Berlin.

Cornes, R. and Hartley, R. (2007) 'Weak links, good shots and other public good games: building on BBV', Journal of Public Economics, Vol. 91, No. 9, pp.1684-1707.

Cornes, R. and Sandler, T. (1996) The Theory of Externalities, Public Goods, and Club Goods, 2nd ed., Cambridge University Press, Cambridge.

Davidsson, P. and Honig, B. (2003) 'The role of social and human capital among nascent entrepreneurs', Journal of Business Venturing, Vol. 18, No. 3, pp.301-331.

DIN 55350-11 (2004) Begriffe zu Qualitätsmanagement und Statistik - Teil 11, Beuth Verlag, Berlin.

Doerner, C., Draxler, S., Pipek, V. and Wulf, V. (2009) 'End users at the bazaar: designing next-generation enterprise-resource-planning systems', IEEE Software, Vol. 26, No. 5, pp.45-51.

Dourish, P. and Bellotti, V. (1992) 'Awareness and coordination in shared workspaces', Proceedings of the 1992 ACM Conference on Computer-supported Cooperative Work, pp.107-114, New York.

Frey, B.S. and Jegen, R. (2001) 'Motivational interactions: effects on behavior', Annales d'Economie et de Statistique, Vols. 63-64, pp.131-154.

Friberg, T., Prödel, S. and Koch, R. (2011) 'Information quality criteria and their importance for experts in crisis situations', Proceedings of the 8th International ISCRAM Conference, Lisbon, Portugal.

Hirshleifer, J. (1983) 'From weakest-link to best-shot: the voluntary provision of public goods', Public Choice, Vol. 41, No. 3, pp.371-386.

Hochberg, Y.V., Ljungvist, A. and Lu, Y. (2007) 'Whom you know matters: venture capital networks and investment performance', The Journal of Finance, Vol. 62, No. 1, pp.251-301.

Johansen, R. (1988) GroupWare: Computer Support for Business Teams, The Free Press, New York.

Kapucu, N. (2006) 'Interagency communication networks during emergencies: boundary spanners in multi-agency coordination', The American Review of Public Administration, Vol. 36, No. 2 , pp.207-225.

Kapucu, N., Arslan, T. and Demiroz, F. (2010) 'Collaborative emergency management and national emergency management network', Disaster Prevention and Management, Vol. 19, No. 4, pp.452-468.

Lazear, E.P. (2005) 'Entrepreneurship', Journal of Labor Economics, Vol. 23, No. 4, pp.649-680.

Le, T.T. and Tarafdar, M. (2009) 'Business ecosystem perspective on value co-creation in the web 2.0 era: implications for entrepreneurial opportunities', International Journal of Entrepreneurial Venturing, Vol. 1, No. 2, pp.112-130.

Ley, B., Pipek, V., Reuter, C. and Wiedenhoefer, T. (2012) 'Supporting improvisation work in inter-organizational crisis management', Proceedings of the 27th International Conference on Human Factors in Computing Systems (CHI '12), Austin, USA.

Lieberman, H., Paterno, F. and Wulf, V. (2006) End-User Development, Springer, Dordrecht, The Netherlands. 
Lundberg, J. and Asplund, M. (2011) 'Communication problems in crisis response', Proceedings of the 8th International ISCRAM Conference, Lisbon, Portugal.

Mainela, T. and Puhakka, V. (2011) 'Role of networks in emergence of international new ventures', International Journal of Entrepreneurial Venturing, Vol. 3, No. 1, pp.5-25.

McAfee, A.P. (2006) 'Enterprise 2.0: the dawn of emergent collaboration', IEEE Engineering Management Review, Vol. 34, No. 3, pp.21-28.

Naumann, F. and Rolker, C. (2000) 'Assessment methods for information quality criteria', Proceedings of the International Conference on Information Quality (IQ), Cambridge, Mass., pp.148-162.

Böert, P. and Werth, J.C. (2012) 'Co-investment networks of business angels and the performance of their start-up investments', International Journal of Entrepreneurial Venturing (accepted), this issue.

Olson, M. (1965) The Logic of Collective Action, Harvard University, Cambridge.

Reichling, T., Moos, B., Rohde, M. and Wulf, V. (2010) 'Towards regional clusters: net2working events, collaborative research, and the business finder', in: Randall, D. and Salembier, P. (Eds.): From CSCW to Web 2.0: European Developments in Collaborative Design, Springer, pp.43-61.

Reuter, C., Marx, A. and Pipek, V. (2012) 'Crisis management 2.0: towards a systematization of social software use in crisis situations', International Journal of Information Systems for Crisis Response and Management (IJISCRAM), Vol. 4, No. 1, pp.S.1-S.16.

Reuter, C., Pipek, V. and Müller, C. (2009) 'Avoiding crisis in communication: a computersupported training approach to emergency management', International Journal of Emergency Management, Vol. 6, Nos. 3-4, pp.356-368.

Rosenfeld, S.A. (1996) 'Does cooperation enhance competitiveness? Assessing the impacts of inter-firm collaboration', Research Policy, Vol. 25, No. 2, pp.247-263.

Samuelson, P.A. (1954) 'The pure theory of public expenditure', Review of Economics and Statistics, Vol. 36, No. 4, pp.387-389.

Starbird, K. and Stamberger, J. (2010) 'Tweak the tweet: leveraging microblogging proliferation with a prescriptive syntax to support citizen reporting', Proceedings of the 7th International ISCRAM Conference, Seattle, USA.

Vicary, S. (1990) 'Transfers and the weakest-link: an extension of Hirshleifer's Analysis', Journal of Public Economics, Vol. 43, No. 3, pp.375-394.

Vieweg, S., Palen, L., Liu, S.B., Hughes, A.L. and Sutton, J. (2008) 'Collective intelligence in disaster: examination of the phenomenon in the aftermath of the 2007 Virginia tech shooting', in Friedrich, F. and Van de Walle, B. (Eds.) Proceedings of the 5th International ISCRAM Conference, Washington, DC, pp.44-54.

Wang, R. and Strong, D. (1996) 'Beyond accuracy: what data quality means to data consumers', Journal of Management Information Systems, Vol. 12, No. 4, pp.5-33.

Wiedenhoefer, T., Reuter, C., Ley, B. and Pipek, V. (2011) 'Inter-organizational crisis management infrastructures for electrical power breakdowns', Proceedings of the 8th International ISCRAM Conference. Lisbon, Portugal.

Wolf, P. (1999) Konzept eines TQM-basierten Regelkreismodells für ein 'Information Quality Management'(IQM), in Kuhn, A. (Eds.): Verlag Praxiswissen, Dortmund.

Zeist, R.H.J. and Hendriks, P.R.H. (1996) 'Specifying software quality with the extended ISO model', Software Quality Journal, Vol. 5, No. 4, pp.273-284. 


\section{Notes}

1 Especially for state-owned organisations an obligation would be imaginable. Yet, the specific contributions would have to be evaluated. This would involve the difficulty to measure and quantify the quality of the individual information provided. Particularly with regard to a possible crowding-out of intrinsic motivation, such a scheme not seems conducive (Frey and Jegen, 2001).

2 This composition function is technically identical to the income function used by Lazear (2005) which captures the jack-of-all-trades entrepreneur. He assumes that the income depends on different skills as 'input factors' and the weakest attribute limits his success as opposed to specialists who receive income associated with their best skill ('best-shot').

3 However, the quantity of contributions can give an indication of the crisis' intensity. 